Authors' Contribution:

A Study Design

B Data Collection

C Statistical Analysis

D Data Interpretation

E Manuscript Preparation

F Literature Search

G Funds Collection

\section{Physical activity and body image of women: literature review}

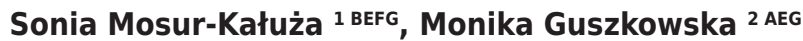 \\ ${ }^{1}$ PhD studies, The Faculty of Physical Education, Józef Piłsudski University of Physical \\ Education in Warsaw, Poland \\ 2 Department of Social and Cultural Foundations of Tourism, The Faculty of Tourism and \\ Recreation, Józef Piłsudski University of Physical Education in Warsaw, Poland
}

\title{
abstract
}

Background This study represents a review of literature on the relationship between recreational physical activity and the body image.

Material/Methods This research encompasses 39 papers published between 2008 and 2015 that were available in the Academic Search Complete database.

Results The results of comparative, prospective, and experimental research are ambiguous. These data suggest both a positive relationship between the body image and physical activity, i.e. a more positive body image among more active people and an improvement in the body image as a result of regular exercise, and a negative relationship, in particular, a more negative body image in persons engaging in "aesthetic" sports.

Conclusions Apparently, this is determined by the type of physical activity, i.e. recreational vs. sport. In the case of the latter, it is determined by the sport discipline chosen by respondents.

Key words body image, physical activity, psychology, women

\section{article details}

Article statistics

Full-text PDF:

Copyright

Indexation:

Funding:

Conflict of interest: Corresponding author:

Open Access License:
Word count: 4,719; Tables: 0; Figures: 0; References: 58

Received: November 2014; Accepted: May 2015; Published: September 2015

http://www.balticsportscience.com

(c) Gdansk University of Physical Education and Sport, Poland

AGRO, Celdes, CNKI Scholar (China National Knowledge Infrastructure), CNPIEC, De Gruyter - IBR (International Bibliography of Reviews of Scholarly Literature in the Humanities and Social Sciences), De Gruyter - IBZ (International Bibliography of Periodical Literature in the Humanities and Social Sciences), DOA), EBSCO - Central \& Eastern European Academic Source, EBSCO - SPORTDiscus, EBSCO Discovery Service, Google Scholar, Index Copernicus, J-Gate, Naviga (Softweco, Primo Central (ExLibris), ProQuest - Family Health, ProQuest - Health \& Medical Complete, ProQuest - Illustrata: Health Sciences, ProQuest - Nursing \& Allied Health Source, Summon (Serials Solutions/ProQuest, TDOne (TDNet), Ulrich's Periodicals Directory/ulrichsweb, WorldCat (OCLC)

This study was conducted under the University of Physical Education statutory research project Ds. 189, “Body image in adolescent girls and young adult women with diverse physical activity", which was financed by the Ministry of Science and Higher Education.

Authors have declared that no competing interest exists.

Sonia Mosur-Kałuża, Department of Social and Cultural Foundations of Tourism, The Faculty of Tourism and Recreation, Józef Piłsudski University of Physical Education in Warsaw, Poland, 00-968 Warszawa, ul. Marymoncka 34; phone: +48 503515 366; E-e-mail: sonia.mosur@gmail.com

This is an open access article distributed under the terms of the Creative Commons Attribution-Non-commercial 4.0 International (http://creativecommons.org/licenses/by-nc/4.0/), which permits use, distribution, and reproduction in any medium, provided the original work is properly cited, the use is non-commercial and is otherwise in compliance with the license. 


\section{INTRODUCTION}

The contemporary woman's body is permanently exposed to environmental assessment and criticism and the body image is an important criterion for self-assessment [1]. The environmental beauty canons [2] and their internalization $[3,4]$ have a significant impact on feelings about one's own body. In a situation where these standards are unrealistic [5] and the media popularize an exaggerated image of a woman, a comparison with those standards may cause a deterioration in self-esteem and lower self-confidence, which can result in depression [6]. Extensive research indicates that women experience lower body satisfaction and higher body image concern than men $[7,8,9,10,11,12]$. Females overestimate their weight and there are more cases of alterations in the body image perception [8].

\section{MATERIAL AND METHODS}

This study undertook a review of literature concerning the body image of individuals participating in different physical activities and who engage in different sport disciplines. The reviewed literature also concerned the influence of physical exercise on the body image. Similar analyses were conducted by Gonçalves et al. [13], who used the Web of Science, Scopus, and SportDiscus data-bases. A review of research on this subject can also be found in an article by Vaquero et al. [14], who conducted analyses of data found in the Medline, ISI Web of Knowledge, and Dialnet data-bases. The collected material indicates that relations between physical activity and body image are complex and ambiguous. The present study, which uses resources found in the EBSCO database entitled Academic Search Complete, comprises references to 39 articles that were published between 2008 and 2015 and 3 before 2006 and had the following terms among their key words or in abstracts: body image, physical activity, sport, recreation, woman, women's sports.

\section{RESULTS}

According to Garner [15], body image is a mental representation of the body shape, the body's size-related features, and the body's condition. Body image depends on several factors:

1. physical (body weight, body-related feelings);

2. interpersonal (judgments from family members, friends, and the peer group; sexual experiences);

3. social and cultural (models promoted mainly by the media and advertising) [16].

Body image consists of the following aspects:

- cognitive - this relates to the body weight and size-related feature and con-tains an assessment of one's attractiveness and physical fitness;

- emotional - level of discontentment with general body appearance, the body's size-related features, and the body's individual parts;

- behavioural - body-oriented activities, including an assessment and control of the body weight, eating habits, clothes and cosmetics aimed at improving beauty, and general physical activity. 


\section{OSitive influence Of Physical aCtivity ON THE BOdy IMAge}

Relationships between physical activity and the body image have been examined with a use of comparative, correlative, prospective, and experimental research. Comparative research includes a comparison between groups undertaking various levels and types of physical activity. It has been observed that more physically active persons are characterized by a more positive body image than persons who are physically non-active [17]. Thus, teenagers aged 12-17 years who actively partici-pated in sports on a regular basis (at least once a week) presented a more positive body image than their physically non-active peers [18].

The Martin-Albo team [19] conducted research with persons participating in fitness centre sport classes lasting 45-120 min at least twice a week. Persons who regularly participated in physical activities and derived pleasure from it perceived themselves better and enjoyed better mental well-being.

Mature women who regularly participated in physical activities had high self-esteem, despite lower levels of contentment with their body image due to excessive body mass. Women who perceived their body shape less favourably, but had a higher social and economic status, revealed higher self-esteem. Therefore, the relationship between physical activity and body-related self-esteem are modified by the social and economic status.

The study also compared sportswomen from various sport disciplines. Research by Abbot and Barber [20] demonstrated that girls practising different sports had varied body images; however, in comparison to girls not engaged in any sport discipline, body image was formed on the basis of its functional rather than aesthetic aspects.

In the dance milieu, the so-called cult of the body can be observed. In research carried out in Poland, a positive relation between dance and self-perception has been observed in the case of both competitive and recreational sports [21].

Research on various kinds of dance has shown a frequent occurrence of dancers who strived for an ideal body shape at the expense of their health. The only exception was belly dancing [22], where there was no pressure for any particular shape of the body. The specificity of this dance allows women to maintain their natural shapes, which results in increased levels of body acceptance.

On the other hand, in research by Pollatou et al. [23], professional dancers revealed higher lev-els of dissatisfaction with particular body areas, but at the same time demonstrated fewer concerns about possible weight gain when compared to amateur dancers.

Correlative research has confirmed positive relationships between physical activity and the body image $[18,24]$. Factors that correlated positively with general and physical self-esteem included the frequency of participation in physical activities, the duration of training sessions, training experi-ence, and satisfaction and pleasure from physical activity.

Prospective research has shown that physical activity worked as a protective buffer against dis-contentment with body image [25]. In addition to that, Telford et al. [26] observed that early devel-opment of eye-motor coordination 
favoured the development of body image in children. Children with better eye-motor coordination were characterized by better body image [26].

Evidence that most strongly has attested to the favourable effect of physical exercise on the body image can be ascertained from research in the experimental mode [27]. This research has demonstrated the positive influence of physical activity among girls practising athletics both on their confidence and contentment with their bodies.

Research carried out by the Burgess team [28] led to the conclusion that participation in anaerobic dancing classes improved physical auto-perception and the relation with one's own body. The results indicated a considerably more positive self-assessment of the body's attractiveness and a significantly greater physical self-esteem in young women who initially displayed a low level of acceptance towards their own bodies. Physical activity had a positive impact on auto-perception, but its effect was not long lasting [28].

While examining the influence of body-shaping on the body image among women, it has been observed that the body image improved as early as after one 60-minute training session [29].

The influence of aerobic and conditioning exercise on the body image has also been compared. The results showed that aerobic exercise led to more benefits and better self-image [30].

As the majority of the mentioned studies have been conducted with adolescents or young adults, the Seguin [31] team studied the effect of strength training on the body image of older rural woman (62 \pm 12 years). The 10-week Strong Woman Program included training sessions BI-weekly. The results showed that strength training was accomplished with meaningful improvements in numerous dimensions of the body image among rural aging woman [31].

The previous research of the Knepp team [32] indicated that there is a relationship between physical exercise and the depression symptoms and that it could work in both directions [32, 33, 34]. According to the research, a higher level of physical activity is indirectly connected with a better body image, and a lower drive to exercise was associated with the top quartile depression group. The finding that higher Modified Beck Depression Inventory scores result in more body, eating, and exercise comparisons relates to previous findings that depression can lead to body dissatisfaction [35, 36, 37]. Previous work has focused more on women (not both sexes) and younger samples than this study [32].

\section{Negative (OR NO) INFluence Of Physical activity ON the bOdY image}

Though it is widely believed that activity has a positive influence on the body image [29], much scientific research shows an inverse relationship, or lack of any significant correlation. In research involving mature women, the Kerksick team [38] observed positive changes in the body image only in those groups in which physical exercise had been combined with a diet. Physical exercise itself did not generate any changes in the body image. 
Research by Monteiro et al. [25] showed that higher levels of physical activity of children aged 10-17 years did not lead to deformations of body image (a difference between the perceived and the actual body shape); at the same time, physical activity had a protective effect on discontentment with one's body image. A similar conclusion was drawn by Corbett et al. [39]. The results established a lack of difference in body satisfaction and in the concept of the ideal body between the diverse gender roles and physical activities, which leads to consideration that the resolution to work out can have a different reason, distinguishable from appearance modification. The main point of the study was that physical activity which does not modify significantly the body does not interfere with cultural expectations for the female body.

In the Spanish population it was established that the level of physical activity continuously de-creased from primary school to university age [25], while the body image was not subject to significant changes over this period of time. Nor had any direct relationship between the level of physical activity and body image been stated. However, it has been proven that physical activity correlated with BMI (Body Mass Index), and that the value of BMI correlated with the body image [25].

Research on the body image by Prichard and Tiggemann [40] aimed at comparing endurance and strength training in a fitness club with individual training not organised by a club. Participants in organised yoga classes were also involved in the study. It was established that endurance training organised outside clubs had a positive relationship with the participants' body image. Confidence was the highest among participants of organised gym classes, whereas nutritional disorders were most often found among persons who participated in endurance training (both in the case of individual training and classes organised by the fitness club). Interpretation of the body image among women participating in yoga classes was different from that of other respondents. This was explained by the fact that the motivation of women participating in these classes was directed at achieving the unity of body and mind and increasing body awareness, not at an immediate slimming effect.

In each culture, society, and social group there are specific canons of external appearance. In particular, the sport environment encourages formation-specific models of the body image, and, in the wake of it, pressure on particular body weight and external appearance. This phenomenon can have negative aftermath for women who practise competitive sports [41], but not for those prac-tising recreational sports.

Body image has a special meaning in many competitive sport disciplines, including in "aesthetic" sports, such as rhythmic gymnastics [41], body building [42], synchronised swimming [41], figure skating [43], dance [22, 23, 28, 44,45 ] and cheerleading [46], as well as sports in which the ratio between strength and body mass is important (e.g. athletics) [47] or sports with body mass grading [48] and horse riding [49]. In "aesthetic" sports, which promote a slim body shape, both the general and physical image of the body was significantly lower than among women practising other sport disciplines, or women who were not engaged in any sport activity. The same refers to their self-esteem, especially the part connected with their physical attractiveness. Additionally, sportswomen who practised "aesthetic" disciplines were more vulnerable to eating disorders than women who were physically non-active, 
although there were no differences between these groups of women in terms of general discontentment with their bodies.

Aesthetic motivations found in fitness activities (e.g. aerobic, dance, etc.), corresponded with a worse body image and a smaller awareness of one's physical attractiveness, as opposed to team sports (such as football, basketball), which led to a healthier body image. There were multilateral relationships between self-perception, the type of sport, and body discontentment [50].

Women who practise these sports recreationally should pay attention to factors that can lead to the deterioration of sportswomen's body image. These include a conviction that improved sport results can be achieved by body mass regulation. A reduction in the body mass aimed at improving performance can lead to eating disorders; it also makes them predictable (which does not work in the reverse direction) [43]. The most common disorders related to professional (non-recreational) "aesthetic" sports are anorexia and bulimia. A higher risk of anabolic steroids intake can be observed in the case of bodybuilding [42].

Another relevant factor is the pressure exerted by the sport environment, namely judges, coaches, and other team players. There is also the stress connected with sport event clothes which overly expose and emphasise the body shape [51]. Research by Muscat and Long [52] showed that women who practised sport actively and those who were recreationally active were very sensitive to critical comments. The more negative the comments, the higher the likelihood of developing eating disorders. At the same time, deeper engagement entailed an increased number of critical comments. According to the theory of objectification [53], women who received more negative comments more often experienced intense negative emotions (embarrassment, anxiety) than positive emotions, irrespective of whether or not they undertook sport or recreational activity [25].

Research carried out by Schluger [45] proved that women dancers of modern dance and classical ballet revealed disturbed dietary habits. Female ballet dancers were characterised by substantially higher fear of bulimia and eating, and more often undertook stimulated feeding, than women practising modern dance. The risk of developing eating disorders in the ballet group was high. Thus, women who practise ballet dance are more prone to eating pathologies than modern dancers.

Because physical activity may, despite common beliefs, correspond to a deterioration in the body image, sportswomen (especially those practising sport disciplines where appearance plays an important role) should have access to professional psychological care. It should also be provided for women who practise recreational sports and are not under such professional care. This care would allow them to become aware of threats posed by an excessive focus on their appearance.

In "aesthetic" sports, emphasis on a slim body shape should be minimised, especially during puberty, which is the formative phase of the body image [45], as self-esteem among young women is sensitive to the opinions of others. To achieve this correct focus, preventive programmes that target coaches and parents should be introduced. One study on the effectiveness of such a program showed that it did not trigger changes in girls' body image; it did, however, reduce pressure from their sports clubs to have a slim body shape. 
Researchers have suggested introducing the Scale of Independent Body Weight in competitive sports due to its practical applications in screening tests and the ability to identify pressures on sportswomen concerning body weight. The scale contains body mass norms for specific sport disciplines. Each abnormality is a signal to the coach and sportswomen themselves that the risk of eating disorders is increasing. With regard to the personal level of engagement, women who practise sport recreationally can use this scale as a comparative benchmark.

Promotion of healthy lifestyle would benefit and educate parents, coaches, and medical staff regarding the identification of disturbed eating symptoms in the case of competitive sports [48]. Coaches and parents should be aware of possible eating disorders in the sport environment. They should detect them early and take preventive measures.

\section{CONCLUSIONS}

Women who practise sport in a recreational form are less exposed to a negative influence of physical activity on their body image than women who practise sports competitively. The former, however, should not forget about the threats of the sport discipline they choose. The results of this study itemise factors that cause the body image to deteriorate. These are:

1. focus on maximal achievements (breaking records at the world levels) [54];

2. participation in sport disciplines which emphasise aesthetic values [50], disciplines aimed at improving appearance, or those where body weight categories are used [48];

3. domination of anaerobic over aerobic efforts [30];

4. transition from an aesthetic to a functional body image [20];

5. numerous negative comments related to appearance [52];

6. early start of a sporting career, over-training, sport injuries, unfortunate coach behaviour [48];

7. solo conditional training as opposed to group training in fitness clubs [40];

8. excessive internalisation of the media message on one's sport discipline, or excessive worry and distress over information from the media [47];

9. bad family situation and poor autonomy support at respective age levels [55];

10. increased body weight or overweight [23];

11. advanced age and reduced body demand for energy [56];

12. low social status [30];

13. eating disorders [57];

14. disturbed eating habits (dietary practices) [45];

15. low level of engagement in physical activity, unhealthy lifestyle [57].

Physically active women tend to have more positive feelings about their bodies than women who lead a sedentary life [58]. Yet we should bear in mind that the aforementioned factors may either directly or indirectly change the correlation between physical exercises and the body image from positive to negative. 


\section{REFERENCES}

[1] DCash TF, Thériault J, Annis NM. Body image in an interpersonal context: adult attachment, fear of intimacy, and social anxiety. J Soc Clin Psychol. 2004;23:89-103.

[2] Benbow-Buitenhuis A. A feminine double-bind? Towards understanding the commercialisation of beauty through examining anti-ageing culture. Soc Alternatives. 2014;33:43-49.

[3] Suisman JL, O'Connor SM, Sperry S, et al. Genetic and environmental influences on thin-ideal internalization. Int J Eat Disorder. 2012;45(8):942-948.

[4] Ferguson C, Muñoz M, Garza A, Galindo M. Concurrent and prospective analyses of peer, television and social media influences on body dissatisfaction, eating disorder symptoms and life satisfaction in adolescent girls. J Youth Adolescence. 2014;43:1-14.

[5] Bradford JW, Petrie TA. Sociocultural factors and the development of disordered eating: A longitudinal analysis of competing hypotheses. J Couns Psychol. 2008;55:246-262.

[6] Ricard N, Beaudry S, Pelletier L. Lovers with happy feet: the interdependence of relationship and activity factors for individuals dancing with a romantic partner. J App Soc Psychol. 2012;42:939-963.

[7] Zaccagni L, Masotti S, Donati R, Mazzoni G, Gualdi-Russo E. Body image and weight perceptions in relation to actual measurements by means of a new index and level of physical activity in Italian university students. J Transl Med. 2014;12:1-16.

[8] Nelia Soto Ruiz M, Marín Fernández B, Aguinaga Ontoso I, et al. Analysis of body image perception of university students in Navarra. Nutr Hosp. 2015;31:2269-2275.

[9] Mintem GC, Gigante DP, Horta BL. Change in body weight and body image in young adults: a longitudinal study. BMC Public Health. 2015;15:1-7.

[10] Téllez Suárez E, Castillo Biscari N, García Quesada S, et al. Satisfaction with body image in a university population of the Comunidad de Madrid. Nutr Hosp. 2015;31:1423-1426.

[11] El Ansari W, Dibba E, Stock Ch. Body image concerns: levels, correlates and gender differences among students in the United Kingdom. Cent Eur J Public Health. 2014;22:106-117.

[12] Dalcin Gattiboni B, da Silva de Sá A, Pozzobon D, et al. Sports experiences and perceptions of body image of adolescents of private high schools. Rev Salusvita. 2015;34:13-26.

[13] Gonçalves CO, Campana AN, Tavares MC. The influence of physical activity on body image: A literature review. Motricidade. 2012(2);8:70-82. Portuguese.

[14] Vaquero R, Alacid F, Muyor J, López P. Body image; A literature review. Nutr Hosp. 2013;28:27-35. Portuguese.

[15] Garner D. The 1997 body image survey results. Psychol Today. 1997;30:30-44.

[16] Glebocka A. Niezadowolenie z wyglądu a rozpaczliwa kontrola wagi [Dissatisfaction with the appearance of a desperate weight control]. Krakow: Impuls; 2009. Polish.

[17] Campbell A, Hausenblas HA. Effects of exercise interventions on body image: a meta-analysis. J Health Psychol. 2009:14:780-793.

[18] Contreras O, Fernández J, García L, Palou P, Ponseti J. Relationship in adolescents between physical self-concept and participating in sport. Rev Psicol Deporte. 2010;19:23-39. Portuguese.

[19] Martín-AlboJ, Núñez J, Domínguez E, León J, Tomás J. Relationships between intrinsic motivation, physical self-concept and satisfaction with life: A longitudinal study. J Sports Sci. 2012;30:337-347.

[20] Abbott B, Barber B. Differences in functional and aesthetic body image between sedentary girls and girls involved in sports and physical activity: Does sport type make a difference? Psych Sport Exerc. 2011;12:333-342.

[21] Jakubiec B, Sekowski A. Obraz ciała u tancerzy [Body image in dancers]. Studia z Psychologii w KUL. 2005; 14:93-106.

[22] Downey D, Reel J, SooHoo S, Zerbib S. Body image in belly dance: integrating alternative norms into collective identity. J Gender Study. 2010;19:377-393.

[23] Pollatou E, Bakali N, Theodorakis Y, Goudas M. Body image in female professional and amateur dancers Res Dance Educ. 2010;11:131-137.

[24] Telleria-Aramburu N, Sánchez C, Ansotegui L, Rocandio AM, Arroyo-Izaga M. Influence of sport practice and physical exercise on anthropometric indicators and weight satisfaction in men university students: a pilot study. Nutr Hosp. 2015;31:1225-1231.

[25] Monteiro M, Amaral T, Oliveira B, Borges N. Protective effect of physical activity on dissatisfaction with body image in children - A cross-sectional study. Psychol Sport Exerc. 2011;12:563-569.

[26] Telford RD, Cunningham R, Telford RM, Olive L, Byrne D, Abhayaratna W. Benefits of early development of eye-hand coordination: Evidence from the LOOK longitudinal study. Scand J Med Sci Sports. 2013;23:263269

[27] Debate R, Gabriel K, Zwald M, Huberty J, Zhang Y. Changes in psychosocial factors and physical activity frequency among third- to eighth-grade girls who participated in a developmentally focused youth sport program: A preliminary study. J School Health. 2009;79:474-484.

[28] Burgess G, Grogan S, Burwitz L. Effects of a 6-week aerobic dance intervention on body image and physical self-perceptions in adolescent girls. Body Image. 2006;3:57-66.

[29] Scarpa S, Nart A, Gobbi E, Carraro A. Does women's attitudinal state body image improve after one session of posture correction exercises? Soc Behav Person: Internet J. 2011;39:1045-1052.

[30] Khodamoradpoor M, Hoseini S. M, Yektayar M, Mohamadi S. The Effect of aerobic exercise and resistance training on women's body image. Archives Appl Sci Res. 2012;4:2345-2349. 
[31] Seguin RA, Eldridge G, Lynch W, Paul LC. Strength training improves body image and physical activity behaviors among midlife and older rural women. J Extension. 2013;51,4FEA2.

[32] Knepp M, Yoza JJ, Quandt EA. Higher modified beck depression inventory scores are associated with body, eating, and exercise comparisons but decreased exercise amounts. Percept Motor Skill. 2015;120:945-959.

[33] Haugen T, Johansen BT, Ommundsen Y. The role of gender in the relationship between physical ac-tivity, appearance evaluation and psychological distress. Child Adolescent Psychiat Ment Health. 2014;19:24-30.

[34] Asare M, Danquah SA. The relationship between physical activity, sedentary behaviour and mental health in Ghanaian adolescents. Child Adolescent Psychiat Ment Health. 2015;9:1-8

[35] Sides-Moore L, Tochkov K. The thinner the better? Competitiveness, depression and body image among college student women. Coll Student J. 2011;45:439-448

[36] Rosenström T, Jokela M, Hintsanen M, et al. Body-image dissatisfaction is strongly associated with chronic dysphoria. J Affect Disorders. 2013;150:253-260.

[37] Jackson K, Janssen I, Appelhans B, et al. Body image satisfaction and depression in midlife women: the Study of Women's Health Across the Nation (SWAN). Arch Women Ment Hlth. 2014;17:177-187.

[38] Kerksick C, Thomas A, Campbell B, et al. Effects of a popular exercise and weight loss program on weight loss, body composition, energy expenditure and health in obese women. Nutr Metab. 2009;14:6-23.

[39] Corbett CA, Campana ANNB, Tavares MCGCF. Physical activity, gender and body image. Rev Salusvita 2013;32:307-320. Portuguese.

[40] Prichard I, Tiggemann M. Relations among exercise type, self-objectification, and body image in the fitness centre environment: The role of reasons for exercise. Psychol Sport Exerc. 2008;9:855-866.

[41] Anderson C, Petrie T, Neumann C. Psychosocial correlates of bulimic symptoms among NCAA Division-I female collegiate gymnasts and swimmers/divers. J Sport Exerc Psychol. 2011;33:483-505.

[42] Goldfield G. Body Image, Disordered eating and anabolic steroid use in female bodybuilders. Eat Disord. 2009;17:200-210

[43] Krentz E, Warschburger P. A longitudinal investigation of sports-related risk factors for disordered eating in aesthetic sports. Scand J Med Sci Sports. 2013;23:303-310.

[44] Heiland T, Murray D, Edley P. Body image of dancers in Los Angeles: the cult of slenderness and media influence among dance students. Res Dance Educ. 2008;9:257-275.

[45] Schluger A. Disordered eating attitudes and behaviors in female college dance students: Comparison of modern dance and ballet dance majors. North Am J Psychol. 2010;12:117-128.

[46] Torres-McGehee T, Monsma E, Dompier T, Washburn S. Eating disorder risk and the role of clothing in collegiate cheerleaders' body images. J Athletic Training. 2012;47:541-548.

[47] Swami V, Steadman L, Tovée M. A comparison of body size ideals, body dissatisfaction, and media influence between female track athletes, martial artists, and non-athletes. Psychol Sport Exerc. 2009;10:609-614.

[48] Sundgot-Borgen J, Torstveit M. Aspects of disordered eating continuum in elite high-intensity sports. Scand J Med Sci Sports. 2010;20:112-121.

[49] Torres-McGehee T, Monsma E, Gay J, Minton D, Mady-Foster A. Prevalence of eating disorder risk and body image distortion among national Collegiate Athletic Association Division I varsity equestrian athletes. J Athletic Training. 2011;46:431-437.

[50] Fernández J, Onofre R, García L, Villora S. Physical self-concept depending on the kind of physical activity practised and motivation to it. Revista Latinoamericana de Psicología. 2010;42:251-263.

[51] Reel J, SooHoo S, Petrie T, Greenleaf C, Carter J. Slimming down for sport: Developing a weight pressures in sport measures for female athletes. J Clin Sport Psychol. 2010;4:99-111.

[52] Muscat A, Long B. Critical comments about body shape and weight: Disordered eating of female athletes and sport participants. J Appl Sport Psychol. 2008;20:1-24.

[53] Fredrickson BL, Roberts TA. Objectification theory. Psychol Women Quart. 1997;21:173-206.

[54] de Bruin A, Oudejans R, Bakker F, Woertman L. Contextual body image and athletes' disordered eating: The contribution of athletic body image to disordered eating in high performance women athletes. Eur Eat Disord Rev. 2011;19:201-215.

[55] Blackmer V, Searight R, Ratwik S. The Relationship between eating attitudes, body image and perceived family of origin climate among college athletes. North Am J Psychol. 2011;13:435-446.

[56] Le Yen-Chi L, Rahman M, Berenson A. Perceived weight gain as a correlate of physical activity and energy intake among white, black, and Hispanic reproductive-aged women. J Women's Health. 2010;19:1987-1993.

[57] Korn L, Gonen E, Shaked Y, Golan M. Health perceptions, self and body image, physical activity and nutrition among undergraduate students in Israel. PLoS ONE. 2013;8:1-7.

[58] Dorak F. Self-esteem and body image of Turkish adolescent girls. Soc Behav Person: An Int J. 2011;39:553561

Cite this article as: Mosur-Kałuza S, Guszkowska M.

Physical activity and body image of women: literature review

Balt J Health Phys Act 2015; 7(3): 29-37 